\title{
Manometria Anorretal no Divertículo de Reto
}

\author{
Anorectal Manometry in Rectal Diverticulum
}

\section{CARLOS AUGUSTO REAL MARTINEZ'; ROGÉRIOTADEU PALMA²; RENÉCREPALDI FILHO ${ }^{3}$; HERMÍNIOCABRAL DE REZENDE JÚNIOR ${ }^{4}$; RONALDO NONOSE ${ }^{5}$;ELSON FONTANAMARGARIDO ${ }^{6}$}

\author{
${ }^{1}$ Professor Adjunto Doutor do Programa de Pós-graduação em Ciências da Saúde da Universidade São \\ Francisco, Bragança Paulista, São Paulo, Brasil; ${ }^{2}$ Médico Assistente do Serviço de Gastroenterologia \\ Cirúrgica do Hospital do Servidor Público do Estado de São Paulo (IAMSPE), São Paulo, Brasil; ${ }^{3}$ Médico \\ Assistente da Disciplina de Cirurgia Geral da Faculdade de Medicina do ABC, Santo André, São Paulo, Brasil; ${ }^{4}$ \\ Médico Assistente do Serviço de Cirurgia da Chyrus Médica, Santo André, São Paulo, Brasil; ${ }^{5}$ Professor \\ Assistente Mestre do Serviço de Cirurgia Geral do Hospital Universitário São Francisco, Bragança Paulista, \\ São Paulo, Brasil; ${ }^{6}$ Professor Livre-Docente do Departamento de Cirurgia da Faculdade de Medicina da \\ Universidade de São Paulo, São Paulo, Brasil.
}

MARTINEZ CAR; PALMART; CREPALDI FILHO R; REZENDE JÚNIOR HC; NONOSE R; MARGARIDO NF. Manometria Anorretal no Divertículo de Reto. Rev bras Coloproct, 2010;30(1): 023-030.

RESUMO: Divertículo localizado no reto é um achado excepcional, estimando-se que existam pouco mais de 50 casos publicados. A doença apresenta aspectos controversos, quanto a ser de origem congênita ou adquirida. Recentemente, distúrbios defecação vêm sendo relacionado à maior possibilidade do desenvolvimento da doença. Contudo, até a presente data, as alterações manométricas em portadores de divertículo do reto ainda não foram estudadas. Objetivo: O objetivo do presente estudo é demonstrar os resultados de estudo eletromanométrico anorretal, realizado em dois doentes portadores divertículo do reto. Casuística e Método: Um homem e uma mulher, com 56 e 58 anos, respectivamente, foram submetidos à colonoscopia, enema opaco, ultrassonografia endorretal e ressonância magnética da pelve, para confirmação e documentação diagnóstica de divertículo localizado no reto. Os enfermos foram submetidos à eletromanometria anorretal com cateter de oito canais sob perfusão de água a $0,3 \mathrm{ml} / \mathrm{min} /$ canal, através de sistema de infusão capilar pneumático e hidráulico. Resultados: $O$ resultado dos exames em ambos os doentes mostrou perfil pressórico esfincteriano normal, tanto em repouso, como em contração voluntária máxima, não se encontrando assimetrias esfincterianas. O reflexo reto-anal inibitório encontrava-se presente e dentro de valores normais, assim como a sensibilidade e complacência retal. A análise pelo vetor volume não mostrou alterações significativas concluindo-se por estudo manométrico ano-retal normal. Conclusão: $O$ estudo manométrico anorretal não demonstrou existência de distúrbios pressóricos nos esfíncteres anorretais reforçando a possibilidade de que o divertículo de reto possa ter origem congênita, desenvolvendo-se em pontos onde exista maior fraqueza da parede retal.

Descritores: Divertículo; Divertículo/congênito; Reto; Manometria.

\section{INTRODUÇÃO}

A doença diverticular dos cólons (DCC) apresenta importância clínica crescente em todo mundo, por sua alta prevalência, principalmente nos países industrializados. ${ }^{1}$ Nos EUA estima-se que $80 \%$ da po- pulação, acima dos oitenta anos, seja portadora da DDC. ${ }^{1}$ Em contraste, o comprometimento do reto por divertículos é uma possibilidade raramente descrita. ${ }^{2,3,4}$ A primeira publicação data de 1911, onde o autor descreve nove casos de divertículo de reto (DR) que evoluíram com diverticulite, chamando a atenção para a

Trabalho realizado no Serviço de Coloproctologia da Chyrus Médica, Santo André, São Paulo, Brasil.

Recebido em 15/09/2009

Aceito para publicação em 19/10/2009 
importância, na vigência da complicação, do diagnóstico diferencial com o câncer do reto. ${ }^{5}$ Posteriormente, revisão de 100 doentes portadores de DCC encontrou, em quatro deles, divertículos de reto (DR). ${ }^{6}$ Govoni et al. em 1974, revisando casuística publicada encontraram 29 casos desde a descrição inicial. ${ }^{7}$ Duas décadas mais tarde, nova revisão encontrou 34 casos, acrescentando mais cinco, diagnosticados, como achado acidental, em um total de 7.200 doentes submetidos à enema opaco por diferentes enfermidades. ${ }^{8}$ Atualmente, estima-se que existam pouco mais 50 casos publicados. ${ }^{9,10,11,12,13}$

A etiopatogenia do DR ainda não se encontra totalmente esclarecida. ${ }^{1,12}$ Existem dúvidas quanto a doença ser de origem congênita ou adquirida. A presença de todas a camadas da parede cólica, tornandoo um divertículo verdadeiro e a possibilidade de acometer recém-nascidos, sugerem que possam ter origem congênita. ${ }^{1,12,14}$ Todavia, não se descarta a possibilidade de possam desenvolver-se ao longo da vida, por traumatismo da parede retal ou condições clínicas que aumentem a pressão no interior do reto e canal anal. É possível, em doentes constipados ou com distúrbios de defecação, que alterações da pressão na região anorretal possa ser um dos fatores relacionados ao desenvolvimento da doença. ${ }^{10,12}$ Todavia, do melhor do nosso conhecimento, nenhum estudo avaliou possíveis alterações manométricas em portadores de DR. Assim sendo, o objetivo do presente relato é avaliar a possibilidade de que existam alterações manométricas em dois doentes portadores de DR.

\section{RELATO DOS CASOS}

\section{Caso $1^{15}$}

Homem, 56 anos, obeso, com queixa, de sangramento e prolapso de mamilos hemorroidários às evacuações há seis meses. Possuía antecedentes de hipertensão arterial tratada, tendo sido internado, há quatro anos, com quadro de diverticulite aguda do cólon sigmóide. No exame físico apresentava-se corado com PA de 170x100 mmHg referindo, ao exame do abdômen, discreto desconforto à palpação profunda de fossa ilíaca esquerda. $\mathrm{O}$ exame proctológico mostrava à inspeção dinâmica, prolapso de mamilos hemorroidários durante as manobras de esforço e ao toque retal a tonicidade esfinceriana era normal. $\mathrm{Na}$ retoscopia havia sinais de sangramento oriundo do mamilo hemorroidário anterior direito, tendo sido reali- zada, nessa mesma oportunidade, ligadura elástica isolada do mamilo com sangramento. Há seis centímetros da margem anal, em parede lateral esquerda, encontrou-se divertículo isolado do reto, com óstio com aproximadamente quatro centímetros de diâmetro e colo curto, medindo aproximadamente dois centímetros de profundidade não apresentando sinais de sangramento. A ressonância magnética da pelve demonstrou presença de DCC restrita ao cólon esquerdo, mostrando ainda, como achado de exame o DR (Figura 1A). A ultrassonografia endorretal constatou que a parede do divertículo era constituída por todas as camadas da parede retal. A mucosa no interior do divertículo era lisa, com coloração normal com vasos submucosos facilmente identificados. (Figura 1B).

\section{Caso 2}

Mulher, 58 anos, com dois antecedentes de dois partos normais, submetida perineoplastia há 10 anos, queixava-se de constipação intestinal há 20 anos, necessitando uso contínuo de laxantes para evacuar em dias alternados. Apresentava dor constante em região de fossa ilíaca esquerda e, ocasionalmente, episódios súbitos dor anorretal, de forte intensidade, em caráter de espasmo, que duravam em média um minuto, principalmente durante a madrugada e que melhoravam espontaneamente. Procurou serviço especializado tendo sido diagnosticada como portadora de constipação intestinal e proctalgia fugaz. Negava perda sangüínea e sabia ser portadora de DDC, em virtude de diverticulite de sigmóide há sete anos tratada, com sucesso, com dieta e antibioticoterapia. Nos últimos seis meses apresentou piora da abdominal com episódios recorrentes de cólicas em abdômen inferior e fossa ilíaca esquerda que só melhoravam após a evacuação ou com o uso de antiespasmódicos. Ao exame físico apresentava-se corada, normotensa, afebril com desconforto à palpação profunda de fossa ilíaca esquerda, onde era possível palpar-se o cólon sigmóide contraído, mas sem sinais de irritação peritonial. Ao exame proctológico notavamse plicomas, e o toque retal mostrava esfíncteres com tonicidade normal não se tocando massas ou retocele. O enema baritado confirmou o diagnóstico de DDC difusa comprometendo, principalmente, o cólon sigmóide que apresentava redução de sua luz, além de encontrar, como achado de exame, o DR (Figura 2A). À colonoscopia mostrou maior quantidade de divertículos no cólon sigmóide onde ocorria dificuldade da progressão do aparelho que, contudo, não impedia a 

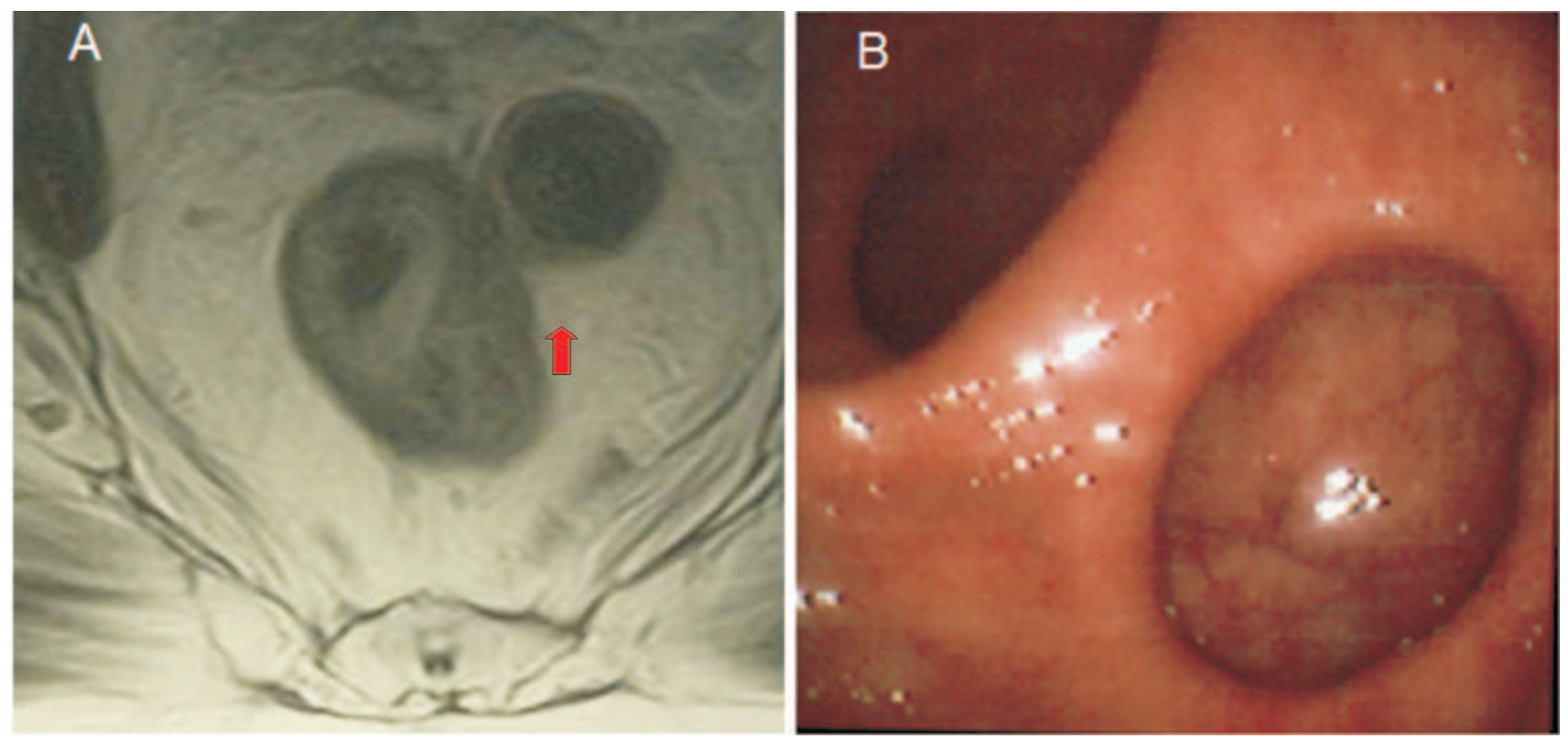

Figura 1 - A) Ressonância magnética da pelve mostrando divertículo na parede retal esquerda (seta). B) Retoscopia mostrando divertículo isolado na parede lateral esquerda do reto.

progressão do exame. A mucosa neste segmento não mostrava sinais de inflamação aguda ou neoplasia. $\mathrm{O}$ exame mostrou que o DR, localizava-se oito centímetros acima da linha pectínea, em parede póstero-lateral direita, com óstio amplo,com aproximadamente três centímetros de diâmetro, colo curto e corpo com dois centímetros de profundidade. A mucosa no interior do DR encontrava-se preservada (Figura 2B). A ultrassonografia endorretal, confirmou, a semelhança do caso anterior, que o DR era formado por todas as camadas da parede retal.

\section{Eletromanometria anorretal}

A eletromanometria foi realizada com o doente em decúbito lateral esquerdo, utilizando-se polígrafo (Insight ${ }^{\circledR}$, Sandhill Scientific, Inc., Highlands Ranch, CO, USA) e cateter de oito canais, com balão de látex na extremidade, sob perfusão de água a $0,3 \mathrm{ml} / \mathrm{min} / \mathrm{ca}-$ nal, através de sistema de infusão capilar pneumohidráulico (Amdofer@ Medical Specialities, Grendale, Wisc, USA). O cateter foi posicionado entre seis e oito centímetros da margem anal. Os valores da pressão foram inicialmente mensurados em repouso três vezes em cada doente. Avaliaram-se o comprimento do esfíncter anal, as pressões de repouso e em contração voluntária máxima. Após medidas das pressões de repouso, o reflexo ano-retal inibidor foi pesquisado por meio da insuflação em balão de látex, posicionado na extremidade do catéter de mensuração. A tabela 1 mostra o comprimento esfincteriano, os valores pressóricos encontrados em repouso e em contração voluntária máxima.

A tabela 2 mostra os resultados da avaliação do limiar sensorial de volume retal, bem como sua complacência total, através de incrementos de volume no balão, avaliando três momentos distintos: primeira sensação evacuatória, sensação de evacuação constante, volume máximo tolerado, assim como o volume infundido para desencadear o RIRA nos dois casos estudados.

O resultado do estudo eletromanométrico mostrou, em ambos os doentes, perfil pressórico esfincteriano normal, tanto em repouso quanto em contração voluntária máxima esfincteriana, não se encontrando assimetrias musculares. O reflexo anorretal inibitório, a sensibilidade e a complacência retal situavamse dentro dos limites normais nos dois enfermos e a análise pelo vetor volume também não mostrava alterações, concluindo-se por estudo manométrico normal em ambos os doentes.

Após o diagnóstico o primeiro doente foi submetido há uma segunda sessão de ligadura elástica não apresentando mais queixas de sangramento retal encontrando-se, atualmente, em acompanhamento anual, nove anos após o diagnóstico, sem demonstrar aumen- 


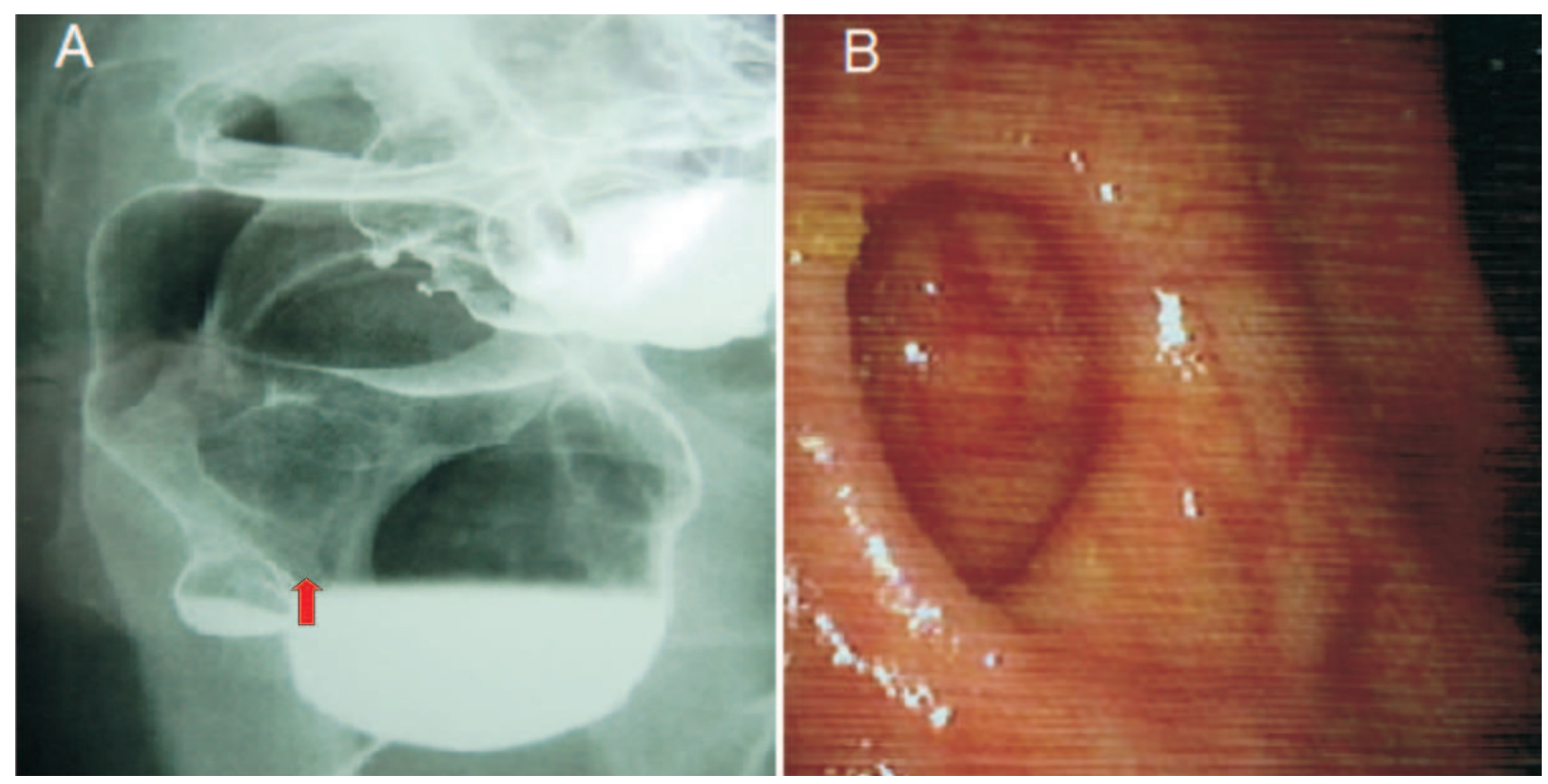

Figura 2 - A) Enema opaco revelando moléstia diverticular no cólon sigmóide e divertículo retal isolado (seta). B) Retossigmoidoscopia confirmando a presença de divertículo isolado do reto na parede lateral direita.

Tabela 1 - Valores pressóricos durante a manobra de retirada contínua da sonda.

\begin{tabular}{lcccc}
\hline & \multicolumn{2}{c}{ Repouso } & \multicolumn{2}{c}{ Contração } \\
& Caso 1 & Caso 2 & Caso 1 & Caso 2 \\
\hline Número de extrações & 3 & 3 & 3 & 3 \\
Esfíncter - comprimento $(\mathrm{cm})$ & 5,8 & 3,5 & 6,0 & 3,8 \\
Pressão máxima (mmHg) & 136,0 & 70 & 171,4 & 124,0 \\
\hline
\end{tabular}

cm = centímetros; $\mathrm{mmHg}=$ milímetros de mercúrio.

to do tamanho do divertículo ou alterações histopatológicas. A segunda paciente após correção do hábito alimentar com introdução de dieta rica em fibras e dextrina resistente de trigo, ingestão de maior volume hídrico diário e atividade física apresentou melhora do quadro doloroso abdominal. No momento encontra-se no segundo ano de acompanhamento ambulatorial, tendo apresentado o último episódio de proctalgia há 18 meses.

\section{DISCUSSÃO}

A presença de DR é raramente descrita estimando-se incidência em torno de 0,08 a 2,4\%., . $^{2,12,16}$ Apresenta maior prevalência entre a $5^{\mathrm{a}}$ e $8^{\mathrm{a}}$ décadas de vida, acometendo com maior freqüência o sexo masculino. ${ }^{12,15} \mathrm{Na}$ maioria dos casos descritos os DR
Tabela 2 - Valores do limiar sensorial de volume retal.

\begin{tabular}{|c|c|c|}
\hline & \multicolumn{2}{|c|}{ Volume retal infundido $(\mathrm{ml})$} \\
\hline & Caso 1 & Caso 2 \\
\hline Nenhuma sensação & 5 & 10 \\
\hline Primeira sensação & 35 & 30 \\
\hline Sensação constante & 55 & 60 \\
\hline Volume tolerável máximo & 140 & 120 \\
\hline RIRA presente & 25 & 40 \\
\hline
\end{tabular}

$m l=$ mililitros $; R I R A=$ Reflexo inibitório reto-anal .

são únicos, podendo encontrar-se até três no mesmo doente. Habitualmente, apresentam maiores dimensões quando comparados aos que acometem o restante do cólon. ${ }^{9,12}$ Estudos mensurando as dimensões dos DR 
em 36 doentes encontraram diâmetro médio de $2,5 \mathrm{~cm}$. 11,17,18 Entretanto, cabe destacar que essas dimensões podem variar com manobras que ocasionem aumento da pressão intra-abdominal. ${ }^{19}$

O DR, geralmente evolui de forma assintomática, sendo achado fortuito durante a realização de exames endoscópicos ou contrastados indicados por outras causas, fato também observado em ambos os doentes do presente relato. ${ }^{2,9,11} \mathrm{O}$ primeiro, apesar de apresentar sangramento às evacuações, a perda sangüínea provinha de mamilo hemorroidário, portanto não relacionada ao DR. Na segunda enferma, não obstante queixar-se de dor anal noturna em espasmo, sugestiva de proctalgia fugaz, era difícil relacionar o quadro doloroso a presença do DR, pois passava vários meses e até anos sem apresentar crises dolorosas. Os DR quando se tornam sintomáticos as queixas, habitualmente, encontram-se relacionadas à presença de complicações, sendo as mais freqüentemente descritas: infecção, perfuração, fistulização, sangramento, prolapso mucoso, defecação obstruída e impactação de fezes no interior do divertículo e a possibilidade de coexistência com o câncer de reto. ${ }^{4,12,18,20}$

A etiopatogenia do DR ainda causa polêmica quanto a doença ser de origem congênita ou adquirida. ${ }^{9,11,14}$ Os que sugerem uma possível origem congênita baseiam-se nas peculiaridades da anatomia muscular da parede retal. ${ }^{13,15}$ Anatomicamente, a parede retal possui maior resistência quando comparada a outros segmentos cólicos sendo, portanto, menos vulnerável aos efeitos do aumento da pressão intrarretal que é menor, e menos constante, quando comparada a de outros segmentos do cólon. Nas porções caudais do reto as tênias livre e omental se fundem para formar uma larga e resistente capa muscular que recobre toda a parede anterior. De maneira semelhante, a tênia mesocólica, forma uma camada muscular longitudinal que recobre a totalidade da parede posterior. ${ }^{4,9,16}$ Assim sendo, as regiões anterior e posterior da parede retal apresentam maior resistência quando comparadas às paredes laterais. Este fato assume grande importância ao constatar-se que na maioria dos casos publicados o divertículo localiza-se justamente nas paredes laterais, região anatômica com menor resistência ${ }^{18}$. Alterações embriológicas, ocasionando maior fragilidade muscular nesses locais, tornariam a parede retal lateral mais vulnerável as variações da pressão no interior do reto durante a defecação. ${ }^{9,18,21}$ Ainda fala a favor de uma provável origem congênita, a baixa prevalência da doença, relatos de DR em recém-nascidos e o fato de que são divertículos verdadeiros possuindo, a semelhança dos divertículos congênitos localizados em outros segmentos do tubo digestivo, todas as camadas da parede retal., ${ }^{92,22}$ A localização dos divertículos nos dois casos apresentados no presente relato parecem corroborar estas evidências, ao verificarmos que em ambos o DR localizava-se na parede lateral. Da mesma forma, a ultrassonografia endorretal confirmou que nos dois doentes o divertículo possuía todas as camadas da parede retal.

Apesar das evidências de uma possível origem congênita, alguns autores acreditam que a enfermidade possa se desenvolver ao longo da vida, pois na maioria dos casos descritos e a semelhança dos doentes do presente relato, acometem indivíduos na mesma faixa etária da DDC e, freqüentemente, ambas as doenças encontram-se associadas ${ }^{7,8,9,15}$ A alta prevalência de constipação intestinal, tal como ocorre na DDC, e a constatação de que o DR aumenta de tamanho com manobras que elevam a pressão intra-abdominal, fez com que fosse levantada a possibilidade de que qualquer situação clínica que determinasse aumento da pressão no interior da luz do reto pudesse estar relacionada ao desenvolvimento da doença. ${ }^{17,20,21,23}$ Conconrdando com essas evidências ambos os doentes do presente estudo, eram constipados e apresentavam DDC associada.

É possível que as duas teorias possam estar relacionadas ao desenvolvimento da doença. Um ponto de fraqueza na parede retal, de provável origem congênita, talvez possa ser considerado um fator predisponente, enquanto situações clínicas que aumentem a pressão no interior do reto poderiam ser encaradas como fatores desencadeantes ${ }^{21}$. Entre esses fatores desencadeantes a constipação intestinal, impactação recorrente de fezes no reto, atrofia muscular decorrente da senilidade, obesidade com infiltração de gordura na musculatura retal, ausência de estruturas de sustentação (cóccix), trauma anorretal, estenoses anorretais, infecções e traumas cirúrgicos, merecem destaque. ${ }^{9,12}$

Todavia, parece evidente que a fraqueza da camada muscular da parede retal quer por alterações embriológicas quer por traumatismos, apresenta grande importância para desenvolvimento do DR. A importância da integridade da parede retal tornou-se mais evidente quando, recentemente, vem sendo descrita a 
possibilidade de formação de DR, após tratamento cirúrgico da doença hemorroidária pela anorretopexia mecânica (ARM) ou da retocele pela técnica da ressecção transanal do reto por grampeamento (STARR). ${ }^{24,25,26}$ Uma revisão de 45 cinedefecografias de doentes submetidos à ARM ou a técnica de STARR encontrou sete casos de DR após a cirurgia, que se desenvolveram, justamente, sobre a linha de grampeamento $^{25}$. Dos sete casos descritos, cinco ocorreram após ARM e dois após a técnica de STARR. ${ }^{25}$ Em seis desses doentes, os divertículos desenvolveram-se nas paredes anterior e posterior do reto, regiões sabidamente mais resistentes por serem recobertas em sua totalidade pelas camada musculares. O desenvolvimento de DR exatamente nos pontos mais resistentes da parede retal sugere que possa ter ocorrido lesão da camada muscular própria da parede retal durante o grampeamento, reforçando a importância da integridade muscular na gênese da doença. A presença de segmentos da camada muscular própria da parede retal nos espécimes cirúrgicos analisados após a ARM não é infreqüente. ${ }^{27} \mathrm{~A}$ avaliação rotineira de espécimes removidos após a ARM demonstrou presença de tecido muscular em até $62 \%$ do material estudado. ${ }^{26,28}$ Reforçam a possibilidade de traumatismo da parede retal descrições de complicações sépticas, até mesmo fatais, após a ambas os procedimentos. ${ }^{29,30,31,32,33}$ É possível que nos doentes onde ocorreu a formação do DR a lesão da parede retal tenha sido parcial, enquanto nos doentes, onde houve formação de fístulas ou abscessos retrorretais o traumatismo tenha atingido todas as camadas da parede retal. É bem provável que o desenvolvimento de DR após as essas intervenções, esteja relacionado a erros técnicos durante a execução do procedimento, tais como o englobamento da camada muscular durante a confecção da sutura em bolsa. ${ }^{34}$ Outras complicações como estenoses na linha de grampeamento por sutura em bolsa inadequadamente realizada, distúrbios de defecação ocasionados por grampeamento baixo, redução da distensibilidade e complacência do reto ocasionando alterações da pressão na luz do órgão podem favorecer o desenvolvimento do DR. ${ }^{35,36,37,38,39}$

Referências sugerindo que variações da pressão no interior do reto pudessem estar relacionadas ao desenvolvimento da doença, motivou-nos a realizar estudo manométrico anorretal nesses doentes. ${ }^{14,21}$ Do melhor do nosso conhecimento, a avaliação manométrica anorretal de doentes com DR nunca havia sido anterior- mente publicada. Não obstante, termos avaliado apenas dois doentes, pela própria raridade da doença, os resultados encontrados demonstraram que ambos apresentavam pressões de repouso com valores dentro da normalidade, sugerindo que as pressões do esfíncter interno do ânus encontravam-se preservadas, sem sinais de hipertonia. Os resultados mostraram que o aparelho esfincteriano apresentava comprimento normal, sugerindo que a extensão dos esfíncteres nos portadores de DR não difere da encontrada em outros doentes. Não identificamos pontos de assimetria nas pressões esfincterianas que pudessem justificar a formação do divertículo nas paredes laterais. Os valores normais encontrados durante a manobra de contração voluntária máxima sugerem que o tônus voluntário também se encontrava preservado. A diferença no incremento entre as pressões de repouso e de contração voluntária máxima, que corresponde à pressão do esfíncter externo do ânus, também não demonstrou distúrbios da contractilidade desse músculo.

Valores do limiar de sensibilidade a infusão de volume retal dentro da normalidade sugerem que a presença do DR não modificou a sensibilidade para evacuação nos dois enfermos estudados. É possível que a própria presença do DR pudesse alterar a complacência retal, entretanto não encontramos variações nos valores da complacência quando se pesquisou o volume máximo de infusão tolerável.

Os resultados da avaliação manométrica, não mostraram alterações nas pressões anorretais que pudessem estar relacionadas ao desenvolvimento do DR. Da mesma forma, não demonstraram alterações da sensibilidade ou da complacência do reto. Tais achados reforçam a possibilidade de que lesões da parede retal, talvez seja o fator mais importante para na formação do DR. Contudo, para confirmar essa possibilidade, ainda são necessários estudos com maior número de casos, onde a avaliação da parede retal e da dinâmica da evacuação seja realizada pela ultrassonografia dinâmica endoanal e cinedefecografia, principalmente nos doentes com maior risco de traumatismo da musculatura retal, como aqueles submetidos à ARM ou a técnica de STARR. Caso a incidência de DR após a realização desses procedimentos aumente com o decorrer dos anos é possível considerar os doentes que apresentem grande quantidade de tecido muscular presente no espécime cirúrgico, apresentem maior risco do desenvolvimento do DR. 
ABSTRACT: Diverticulum located in the rectum is an exceptional find with fewer than 50 cases published. The etiology of the diverticulum of the rectum still has controversial aspects regarding its origin is congenital or acquired. Recently, alterations of the evacuative dynamic had been associated with the development of the disease. Nevertheless, until the present date, the manometric alterations in patients with diverticulum of the rectum were not studied. Objective: The aim of the present study is to demonstrate the results of electromanometric study carried out in a patient with isolated diverticulum of the rectum. Case report: A man and a woman, 56 and 58 years-old, respectively, were submitted to colonoscopy, barium enema, endorectal ultrasound and magnetic resonance of the pelvis to diagnose and document the presence of diverticulum located in the rectum. The patients were submitted to manometry using catheter with eight-channel perfusion under water at $0.3 \mathrm{ml} / \mathrm{min} / \mathrm{channel}$, through pneumatic and hydraulic capillary infusion system. The anorectal manometry showed normally sphincter pressure profile both in rest and squeezes pressure state, and did not find sphincter asymmetries. The anorectal inhibition reflex was present with normal values and the sensibility and rectal complaisance were between the normal limits. The vector volume analysis did not show any significant alterations and it was concluded by normal manometric anorectal study. Conclusion: The anorectal manometry study did not demonstrate the existence of pressure disturbances in anorectal sphincter, enhancing the possibility that the rectal diverticulum can be congenital, developing at points where there is major weakness of the rectal wall.

Key words: Diverticulum; Diverticulum/congenital; Rectum; Manometry.

\section{REFERÊNCIAS}

1. Thorson AG, Goldberg SM. Benign Colon: Diverticular disease. In:Wolff BG et al. editors. The ASCRS Textbook of Colon and Rectal Surgery. Springer Science and Business Media, LLC, New York, 2007. 269-85.

2. Piercy KT, Timaran C, Akin H. Rectal diverticula: report of a case and review of the literature. Dis Colon Rectum. 2002;45(8):1116-7.

3. Doyle OW. Large diverticulum of the rectum. Report of a case. Am J. Roentgenol Radium Ther Nucl Med. 1959;81:694695.

4. Tweddell TN. Diverticulitis of the rectum. Can Med Ass J. 1954;70:569.

5. Giffin HZ. Diverticulitis of the rectum. Ann Surg. 1911;53:5337.

6. Spriggs EI, Maxner AO. Multiple diverticula of the colon. Lancet. 1927;212:1067-74.

7. Govoni AF, Smulewicz JJ. Large diverticulum of the canal anal. Case report and review of the literature on anal canal and rectal diverticula. Am J Roentgenol Radium Ther Nucl Med. 1974;121:344-7.

8. Plavsic BM, Taider L, Drnovsek VH, Kogutt MS. Association of rectal diverticula and scleroderma. Acta Radiol. 1995;36:96-9.

9. Walstad PM, Sahibzada AR. Diverticula of the rectum. Am J Surg. 1968;116:937-9.

10. Henry MACA,Vercesi LAP, Lautenschlarger MFM. Divertículo de reto: apresentação de um caso. Arq Gastroenterol. 1982;19:139-41.

11. Lazaro da Silva A, Rodrigues BDS, Mattos MP. Divertículo de reto. Rev Col Bras Cir. 1997;24:449-51.

12. Alves Filho EF, Albuquerque IC, Nunes BLBBP, Nossa FLC, Silva JH, Formiga GJS. Divertículo de reto associado à adenocarcinoma. Rev bras Colo-proctol. 1999;19:267-9.
13. Martinez CAR, Priolli DG, Nonose R, Schmidt KH. Divertículo do reto: relato de caso. Rev Bras Colo-proctol. 2003;23(4):296-301.

14. Sener RN, Melikoglu M, Kaya A. Rectal diverticulum in an infant. Pediatr Radiol. 1991;21:433.

15. Relato de caso publicado na: Rev bras colo-proctol. 2003;23(4):296-301.

16. Spriggs EI, Marxer AO. Multiple diverticula of the colon. Lancet. 1927;1:1067-74.

17. Damron JR, Lieber A, Truman S. Rectal diverticula. Radiology. 1975;115:599-601.

18. Chiu TCT, Bailey HR, Hernandez Junior AJ. Diverticulitis of the midrectum. Dis Colon Rectum. 1983;26:59-60.

19. Halpert RD, Crnkovich FM, Schreiber MH. Rectal diverticulosis: a case report and review of the literature. Gastrointest Radiol. 1989;14:274-6.

20. Chen CH, Jao SW, Lai HJ, Chiu YC, Kang JC. Isolated rectal diverticulum complicating with rectal prolapse and outlet obstruction: case report.

21. Kyaw MM, Haines JO. Rectal diverticula. Radiology. 1971;100:283-4.

22. Weston SD, Schlachter IS. Diverticulum of the rectum. Dis Colon Rectum. 1959; 2:458-64.

23. Edwards VH, Chen MY, Ott DJ, King GT. Rectal diverticulum appearing as a prolapsed rectum. J Clin Gastroenterol. 1994;18:254-5.

24. Folie P, Wolff K, Marti L, Fretz C, Lange J, Hetzer FH. Rectal pocket syndrome after stapled haemorroidopexy.Chirurg. 2009. Epub ahead of print.

25. Sciaudone G, Di Stazio C, Guadagni I, Selvaggi F. Rectal diverticulum: a new complication of STARR procedure for obstructed defecation. Tech Coloproct. 2008;12(1):61-3. 
26. Alabiso ME, Grassi R, Fioroni C, Marano I. Iatrogenic rectal diverticulum in patients treated with transanal stapled techniques. Radiol Med. 2008;113(6):887-94.

27. Sileri P, Stolfi VM, Palmieri G, Mele A, Falchetti A, Di Carlo S, Gaspari AL. Stapled hemorrhoidopexy: a prospective study from pathology to clinical outcome. J Gastrointest Surg. 2007;11:1662-8.

28. Ohana G, Myslovaty B, Arich A, Dreznik Z, Koren R, RathWolfson L. Mid-term results of stapled hemorrhoidopexy for third- and fourth-degree hemorrhoids-correlation with the histological features of the resected tissue. World J Surg. 2007;31:1336-42.

29. Naldini G. Serious unconventional complications of surgery with stapler for haemorrhoidal prolapse and obstructed defecation due to rectocele and rectal intussusceptions. Colorectal Dis. 2009. Epud ahead of print.

30. McCloud JM, Doucas H, Scott AD, Jameson JS. Delayed presentation of life-threatening perineal sepsis following stapled haemorrhoidectomy: a case report. Ann R Coll Surg Engl. 2007;89:301-3.

31. Bönner C, Prohm P, Störkel S. Fournier gangrene as a rare complication after stapler hemorrhoidectomy. Case report and review of the literature. Chirurg. 2001;72:1464-6.

32. Cirocco WC. Life threatening sepsis and mortality following stapled hemorrhoidopexy. Surgery. 2008;143:824-9.

33. Jayne DG, Schwandner O, Stuto A. Stapled transanal rectal resection for obstructed defecation syndrome: one-year results of the European STARR Registry. Dis Colon Rectum. 2009; 52:1205-12.
34. Crepaldi Filho R, Martinez CAR, Palma RT, Priolli DG, Rezende Júnior HC, Waisberg J. Modificação do anuscópio auxiliar (PSA 33) do PPH para facilitar a realização da sutura em bolsa na hemorroidectomia por grampeamento. Rev bras Coloproct 2004;24(4): 365-371.

35. Faucheron JL, Arvin-Berod A, Riboud R, Morra I. Rectal perforation and peritonitis complicating stapled haemorrhoidopexy. Colorectal Dis. 2009. Epub ahead of print.

36. Filho FL, Macedo GM, Dos Santos AA, Rodrigues LV, Oliveira RB, Souza MA. Stapled haemorrhoidopexy transiently decreases rectal compliance and sensitivity. Colorectal Diseases.2009. Epub ahead of print.

37. De Nardi P, Corsetti M, Passaretti S, Squillante S, Castellaneta AG, Staudacher C, Testoni PA. Evaluation of rectal sensory and motor function by means of the electronic barostat after stapled hemorrhoidopexy. Dis Colon Rectum.2008;51:1255-60.

38. Taha MA, Irvine LA, Steele RJ, Campbell KL, Postdefaecation pain syndrome after circular stapled anopexy is abolished by oral nifedipine. Br J Surg. 2005;92:208-10.

39. Giordano P, Bradley BM, Peiris L. Obliteration of the rectal lumen after stapled hemorrhoidopexy: report of a case. Dis Colon Rectum. 2008;51:1574-6.

\section{Endereço para correspondência:}

\section{CARLOS AUGUSTO REAL MARTINEZ}

Rua Rui Barbosa, 255 apto. 32

Santo André (SP) - 09190-370

E-mail: caomartinez@uol.com.br 